\title{
Robotic pancreatectomies
}

This article was published in the following Dove Press journal:

Robotic Surgery: Research and Reviews

27 June 2016

Number of times this article has been viewed

\section{Marco Ramera'}

Isacco Damoli'

Alessandro Giardino²

Claudio Bassi'

Giovanni Butturini²

'General Surgery Unit B, The Pancreas Institute, Verona University Hospital Trust, ${ }^{2}$ Hepato-Pancreato-Biliary Unit, Casa di Cura Pederzoli, Peschiera del Garda, Verona, Italy
Correspondence: Giovanni Butturini Hepato-Pancreato-Biliary Unit - Casa di Cura Pederzoli,Via Monte Baldo, 24 Peschiera del Garda,Verona 37019, Italy Tel +3904 56449187

Fax +390456449140

Email gbutturini@cdcpederzoli.it
Abstract: Pancreatic surgery represents one of the most challenging fields in general surgery. Its complexity is related to the severity of the disease and the technical skills required for surgical approach. Given this, most pancreatic resections are performed through classic open surgery. Minimally invasive approaches are gradually gaining widespread popularity also in this specific setting, as for distal resections and enucleations. The robotic platform, due to its 3-dimensional vision and articulated movements, represents the natural progress of laparoscopic surgery overcoming the technical defaults and opening up the possibility to perform major pancreatic resections as pancreaticoduodenectomies. This review focuses on the impact of robotic platform in pancreatic surgery in terms of surgical and oncological outcome.

Keywords: robotic surgery, pancreatic neoplasms, minimally invasive surgical procedures, pancreatectomy, pancreaticoduodenectomy

\section{Introduction}

Pancreatic surgery represents a complex and difficult chapter of general surgery due to anatomical features as retroperitoneal location and major vessel proximity. For these reasons, classic open approach has been widely advocated as the best technique considering oncological outcomes. Despite the fact that laparoscopic surgery has gradually become the gold standard for several surgical procedures, its reliability and feasibility in pancreatic resections is still a matter of debate; however, minimally invasive approaches are gradually gaining more visibility and importance.

The first pancreatic laparoscopic resection was performed in 1994 by Gagner and Cuschieri, both laparoscopic pancreaticoduodenectomy (LPD) ${ }^{1}$ and laparoscopic distal pancreatectomy (LDP). ${ }^{2}$ Since then, LPD has not acquired popularity because of the high level of technical skills required both for resection and anastomosis and the uncertain results in terms of oncological radicality, in particular, for retroperitoneal lamina. Conversely, due to the absence of anastomosis and the less complex resection, LDP has been widely established as a gold standard treatment for benign distal lesions and a good option for malignant ones despite the initial concerns about oncological outcomes such as surgical margins and lymph node retrieval. ${ }^{3-6}$

Robotic surgery is the latest development in the field of minimally invasive surgery. Introduced in 1990 s by military researches, ${ }^{7}$ this new technology was initially applied for pancreatic resections by Giulianotti et $\mathrm{al}^{8}$ who published the first series of 13 robotic pancreatic resections in 2003. In the same year, Melvin et $\mathrm{al}^{9}$ described the first case of robotic distal pancreatectomy (RDP). Among all the different platforms designed for 
surgical purposes, only one system is widely accepted: Da Vinci Surgical System ${ }^{\circledR}$ (Intuitive Surgical, Sunnyvale, CA, USA). The system consists of three fundamental elements: the surgeon's console (in which the surgeon is seated, with a 3-dimensional (3D) visor and a master console for manipulating the instruments), a patient-side cart (with four articulated arms that reproduce hand movements in the surgical field), and a vision-control system. Robotic surgery enhances the advantages of laparoscopic surgery, such as smaller incisions, lesser blood loss, shorter length of stay, and faster recovery. The robotic platform, compared to laparoscopy, improves the hand-eye coordination, has a better vision due to the full high definition $3 \mathrm{D}$ vision, reduces the natural tremors with no fulcrum effect, uses seven (out of three) degrees of freedom of the instruments (Endowrist technology ${ }^{\circledR}$, Sunnyvale, CA, USA), and last but not the least, gains in ergonomics considering more comfortable sitting for the surgeon.

The aim of this review is to discuss the impact of the robotic platform on pancreatic surgery in terms of surgical and oncological outcomes.

\section{Robotic pancreaticoduodenectomy Indications}

Pancreaticoduodenectomy (PD) is the surgical treatment of periampullary, duodenal, and pancreatic head lesions. The earliest series ${ }^{10,11}$ of Robotic pancreaticoduodenectomy (RPD) included patients with benign or low-grade malignant lesions, in the absence of local invasion of major vessels. Current major series describe an increasing number of robotic resections for malignant disease.

PD is still considered a very challenging and complex procedure considering the resection time, as very delicate manipulation of the uncinate process, portal vein, and mesenteric vessels is required both for pancreatic and biliary anastomosis. Given the above, minimally invasive approaches were rarely advocated for pancreatic surgery. In 2012, only seven centers worldwide had published their experience with LPD of 30 or more patients. ${ }^{12}$ The same authors who described the first LPD concluded that despite its feasibility, LPD would not improve the postoperative outcomes or decrease the admission time. ${ }^{13}$ For these reasons, robotic platforms were expected to be very useful in promoting minimally invasive approaches to pancreatic surgeons such as it happened to minimally invasive prostatectomies becoming the gold standard treatment. As a matter of fact, since the first small series of RPD, ${ }^{8}$ the number of patients has been slowly increasing, although the know-how is still a prerogative of very skilled surgeons; just one series published recently reported 200 cases. $^{10}$

\section{Technique}

Since the first experiences, two techniques have been described for RPD: some groups adopt a hybrid laparoscopic/ robotic approach, while others perform the entire operation robotically. Narula et al ${ }^{14}$ describe a hybrid laparoscopic and robotic approach for PD, in which all the dissection is performed laparoscopically while the robot is reserved for anastomosis and is beneficial in improving the precision and agility in performing sutures. Fernandes and Giulianotti, ${ }^{15}$ the pioneer group of the RPD, advocated a full robot-assisted approach considering that "there is no role for hybrid handassisted or laparoscopic/robotic approaches."

\section{Outcomes}

The variables to consider are operative time, blood loss, conversion rate, incidence of fistula, morbidity, mortality, length of hospital stay, oncological outcomes, and costs (Table 1).

The most recent and largest series published to date with 200 consecutive RPD had a mean operative time of 483 minutes. ${ }^{10}$ The authors retrospectively review their database aiming to identify the learning curve. The most significant improvement in operative times was assessed after 80 procedures (581 minutes for the first 80 cases vs 417 minutes for the last 120 cases; $P<0.001)$. They recorded a median

Table I Outcomes of robotic pancreaticoduodenectomy

\begin{tabular}{|c|c|c|c|c|c|c|c|c|c|c|}
\hline Source & $\mathbf{N}$ & $\begin{array}{l}\text { OR time* } \\
\text { (mean) }\end{array}$ & $\begin{array}{l}\text { EBL } \\
\text { (mean) }\end{array}$ & $\begin{array}{l}\text { Conversion } \\
(\%)\end{array}$ & $\begin{array}{l}\text { RO } \\
\text { (\%) }\end{array}$ & $\begin{array}{l}\text { LN harvest } \\
\text { (mean) }\end{array}$ & $\begin{array}{l}\text { Fistula } \\
\text { (\%) }\end{array}$ & $\begin{array}{l}\text { Morbidity } \\
\text { (\%) }\end{array}$ & $\begin{array}{l}\text { Mortality } \\
\text { (\%) }\end{array}$ & $\begin{array}{l}\text { LOS } \\
\text { (mean) }\end{array}$ \\
\hline Giulianotti et al $2010^{16}$ & 60 & 421 & 394 & 18.3 & 82 & 18 & 31.6 & NR & 3.3 & 22 \\
\hline Narula et al $2010^{14}$ & 5 & 420 & NR & 37.5 & 100 & 16 & 0 & 0 & 0 & 9.6 \\
\hline Zhou et al $201 \mathrm{I}^{21}$ & 8 & 718 & 153 & 0 & 100 & NR & 25 & NR & 0 & 16.4 \\
\hline Lai et al $2012^{20}$ & 20 & 491.5 & 247 & 5 & 73.3 & 10 & 35 & 50 & 0 & 13.7 \\
\hline Chalikonda et al $2012^{19}$ & 30 & 476 & 485 & 10 & 100 & 13.2 & 6.6 & 30 & 3 & 9.8 \\
\hline Boone et al $2015^{10}$ & 200 & 483 & 250 & 6.5 & 92 & 22 & 17 & 67.5 & $3.3^{* *}$ & 9 \\
\hline Chen et al $2015^{17}$ & 60 & 410 & 400 & 1.7 & 97.8 & 13.6 & 13.3 & 35 & 1.7 & 20 \\
\hline
\end{tabular}

Notes: *Time in minutes. **Analyzed in 90 days mortality whereas other authors are referring to 30 days mortality.

Abbreviations: OR, operating room; EBL, estimated blood loss; LN, lymph nodes; LOS, length of stay; NR, not recorded. 
Table 2 Outcomes of robotic distal pancreatectomy

\begin{tabular}{|c|c|c|c|c|c|c|c|c|c|c|c|}
\hline Source & $\mathbf{N}$ & $\begin{array}{l}\text { OR } \\
\text { time* } \\
\text { (mean) }\end{array}$ & $\begin{array}{l}\text { EBL } \\
\text { (mean) }\end{array}$ & $\begin{array}{l}\text { Conversion } \\
\text { (\%) }\end{array}$ & $\begin{array}{l}\text { R0 } \\
\text { (\%) }\end{array}$ & $\begin{array}{l}\text { LN } \\
\text { harvest } \\
\text { (mean) }\end{array}$ & $\begin{array}{l}\text { Fistula } \\
(\%)\end{array}$ & $\begin{array}{l}\text { Morbidity } \\
\text { (\%) }\end{array}$ & $\begin{array}{l}\text { Mortality } \\
\text { (\%) }\end{array}$ & $\begin{array}{l}\text { LOS } \\
\text { (mean) }\end{array}$ & $\begin{array}{l}\text { Spleen } \\
\text { preservation } \\
\text { rate (\%) }\end{array}$ \\
\hline Giulianotti et al $2010^{16}$ & 46 & NR & NR & 6.5 & NR & NR & 20.9 & NR & NR & NR & 50 \\
\hline Waters et al $2010^{30}$ & 17 & 298 & 279 & 12 & 100 & 5 & 0 & 18 & 0 & 4 & 65 \\
\hline Kang et al $201 \mathrm{I}^{31}$ & 20 & 348.7 & 372 & NR & NR & NR & NR & 10 & 0 & 7.1 & 95 \\
\hline Lai and Tang $2015^{32}$ & 17 & 221 & 100 & NR & NR & NR & 41.2 & 47 & 0 & 11.4 & 52.9 \\
\hline Lee et al $2015^{33}$ & 37 & 213 & 193 & 38 & 100 & 12 & 8 & 60 & 0 & 15 & 8 \\
\hline Butturini et al $2015^{34}$ & 22 & 265 & NR & 4.5 & 100 & 11.5 & 50 & NR & 0 & 7 & 27.3 \\
\hline Shakir et al $2015^{35}$ & 100 & 245.7 & 150 & 2 & 95.7 & 12.5 & 42 & 72 & 0 & 6 & NR \\
\hline
\end{tabular}

Note: *Time in minutes.

Abbreviations: OR, operating room; EBL, estimated blood loss; LN, lymph nodes; LOS, length of stay; NR, not recorded.

estimated blood loss of $250 \mathrm{~mL}$. Conversion to open surgery was required for $6.5 \%$ of cases. Statistical improvements in estimated blood loss and conversions to open surgery occurred after 20 cases ( 600 vs $250 \mathrm{~mL}[P=0.002]$ and $35.0 \%$ vs $3.3 \%$ [ $P<0.001]$, respectively). According to the literature, a considerable proportion of patients $(67.5 \%)$ had complications. The incidence of pancreatic fistula decreased after 40 cases ( $27.5 \%$ vs $14.4 \% ; P=0.04)$. The median length of stay was 9 days, with a 90 -day readmission rate of $29.2 \%$. An R0 resection was performed for 184 patients $(92.0 \%)$, with a median lymph node harvest of 22 .

All other series are limited by a small number of patients: only two included more than 50 patients $^{16,17}$ and only five studies compared the results of RPD to open pancreaticoduodenectomy (OPD). ${ }^{17-21}$ None of the aforementioned studies are prospective randomized trials. Several studies demonstrate a reduction in blood loss and length of hospital stay in LPD compared to OPD. Morbidity rate ranges between $0 \%$ and $75 \%$, including $0 \%-35 \%$ incidence of pancreatic fistula; mortality is between $0 \%$ and $4.5 \%$, similar to the open approach. In a meta-analysis, RPD has been shown to be effective in reducing the morbidity $(12 \%) .^{22}$

Comparison of results among all the series showed that there are many biases due to different postoperative protocols in terms of pain management, diet advancement, drain management, and criteria for discharge; moreover, there are considerable differences in surgeons' learning curves. In addition, biases can arise from patient selection: patients with a more advanced radiology stage or with specific intrinsic characteristic such as high BMI are often excluded from a robotic approach.

Considering the fact that the main indications for PD are periampullary and pancreatic head cancers, oncological outcome represents the key point to be considered. Given this mandatory criterion, obvious selection biases are represented by the indication of open approach for obese patients or large tumors and robotic platform for thin patients or small periampullary neoplasms. RPD series obtained a R0 resection in $73.3 \%-100 \%$ of cases. ${ }^{10,14,16,17,19-21}$ The systematic review by Cirocchi et $\mathrm{al}^{23}$ included 13 case series with an average $\mathrm{R} 1$ resection rate of $9 \%$. Another systematic review reported a greater lymph node harvest with any minimally invasive approach compared to open $\mathrm{PD},{ }^{24}$ while a recent metaanalysis that included data from six series showed a higher rate of $\mathrm{R} 0$ resections in the robotic group. ${ }^{25}$ Nevertheless, the median number of lymph nodes harvested in some series ${ }^{17,19,20}$ was not adequate according to the current guidelines.

Costs are one of the most debated aspects of RDP, which include acquisition and maintenance costs. Only two papers compare the average costs of RPD versus OPD, showing an excess of $€ 6,200$ and 7,644 USD with the robotic approach. ${ }^{17,26}$

Even though these results are encouraging, it is important to observe that they are obtained by only a few very skilled minimally invasive surgeons and cannot be considered a standard of care even in high-volume pancreatic centers. Given the above considerations, in experienced centers in which the results of standard PD are excellent, it may be hard to justify the increased operative time, efforts, and resource utilization for RPD.

\section{Robotic distal pancreatectomy}

Outcomes after RDP are outlined in Table 2. Distal pancreatectomy (DP) is the most common minimally invasive pancreatic resection because of the absence of anastomosis. Nowadays, minimally invasive DP is considered safe and feasible and several studies have shown several advantages of the technique compared to open surgery: shorter hospital stay, less transfusion rate, decreased complications, and faster recovery, in addition to cost-effectiveness. The favorable oncological outcome has been extensively established..$^{27,28}$ Despite the large cohort of studies, the National Surgical 
Quality Improvement Program data for 2005-2010 suggest that only $27 \%$ of DP cases were performed laparoscopically in the USA..$^{29}$ Today, in most cases, traditional laparoscopic technique is preferred to the robotic approach, mostly for cost-effectiveness reasons. However, in the last decade, RDP has probably improved the learning curve, conceived as an introductory step to other more complex robotic resections. One again, these studies confirm the safety and feasibility of RDP. ${ }^{16,30-35}$

\section{Indications}

DP is indicated in case of lesions of the pancreatic body-tail. Selection criteria of the patients include: evaluation of BMI and history of previous laparotomy and cardiopulmonary comorbidity. A high BMI does not represent a contraindication for RDP, but visceral fat can increase the difficulty. Expected advantages of minimally invasive approaches in patients with high BMI include faster access to peritoneal cavity, less postoperative pain, faster recovery, and reduced incidence of incisional hernias. Some authors argue that patients with cardiac and pulmonary comorbidities are ideal candidates for RDP, because they could benefit from faster recovery, but major series mostly include patients with BMI $<30 \mathrm{~kg} / \mathrm{m}^{2}$ and without severe comorbidities. Furthermore, randomized trials do not consider this aspect as a criterion for comparison between robotic and other approaches. Besides, tumor characteristics need to be taken under consideration for selecting patients as candidates for RDP. In case of malignant, bulky, and locally advanced tumors and/or tumors proximal to the neck, indication for minimally invasive approaches is questionable: referring the patient to an experienced center is mandatory. Perhaps the robotic platform, more than laparoscopic setting, can potentially extend the indications, once an adequate learning curve is acquired.

\section{Technique}

DP can be associated to splenectomy or not. Splenectomy can be associated to the well-known overwhelming postsplenectomy infections, which have a low $(<1 \%)$ annual incidence but high mortality $(>80 \%) \cdot{ }^{36}$ For these reasons, vaccination protocol against capsulated bacteria (Streptococcus pneumoniae, Haemophilus influenzae, Neisseria meningitidis) is mandatory. Another risk to consider is postsplenectomy thrombocytosis. Spleen-preserving DP is the best procedure for benign lesions, in which the lower number of nodes retrieved is not a deal. Two techniques are described for spleen-preserving DP: Warshaw and Kimura procedures. The Warshaw ${ }^{37}$ technique consists of resection of the splenic artery and vein, considering the preservation of short gastric vessels sufficient for the blood supply and the splenic outflow. Kimura et al's ${ }^{38}$ procedure, which preserves the spleen and the vessels, represents the most frequent approach. Literature reports a more successful spleen preservation rate for laparoscopic technique compared to ODP. ${ }^{30}$ Moreover, some authors have reported superiority of the robotic approach over laparoscopy for spleen preservation, ${ }^{30,31}$ but arriving at conclusions is difficult because of the well-established variability in terms of indication and postoperative approaches, which differ among the centers.

\section{Outcomes}

In many series, longer operative time is reported ${ }^{30-35}$ for robotic compared to laparoscopic approach; this may be explained by the additional docking time. Moreover, laparoscopic and robotic approaches are frequently compared at a different level of the learning curve. A study from our institute shows that the operative time in 22 RDPs was significantly longer than that in last 21 LDPs, but when the first 22 historic laparoscopic cases were included, the difference did not reach statistical significance. ${ }^{34}$ Pittsburgh center first reported the series with shorter operative time for robotic than laparoscopic approach. The same institute has analyzed the learning curve for RDP, identifying a significant decrease in operative time after 40 procedures..$^{35}$

Blood loss is significantly lower for MIDP (minimally invasive distal pancreatectomy) compared to ODP among all the series reported..$^{39}$ This result is attributed to the progress in surgical techniques, vascular sealing devices, and mechanic staplers that improve the safety and efficacy of minimally invasive pancreatic resections.

The conversion rate varies from $0 \%$ to $12 \%$ in major RDP series. ${ }^{40}$ Some authors have reported a lower conversion rate in the robotic series. ${ }^{41,42}$ Conversion to open surgery is associated with higher blood loss and longer length of stay. ${ }^{33}$ Reasons for conversion are high BMI, adhesions, bulky and pancreatic neck lesions, and intraoperative bleeding.

Pancreatic fistula is related to incomplete sealing of pancreatic stump and/or leakage from incompletely closed main pancreatic duct. Incidence ranges from $0 \%$ to $70 \%$ among the series reported, but it is not related to the open versus laparoscopic or robotic approach. ${ }^{11,39}$ Ranges are wide due to the lack of homogeneity in pancreatic fistula definition despite the availability of an international definition and classification currently (the International Study Group on Pancreatic Fistula $\mathrm{a}^{43}$ ). Moreover, some series report the overall incidence, while others report only clinically relevant ones. A large 
meta-analysis also demonstrated that different treatment of the stump (stapler, suture, or nothing) is not associated with variation of incidence of pancreatic fistula. ${ }^{44}$

Length of hospital stay is shorter after minimally invasive DP (RDP: 4-9 days, ${ }^{11,39}$ LDP: 5-22 days ${ }^{45}$ ) compared to ODP (6-27 days) in major series. ${ }^{46}$

Patients undergoing MIDP tend to have a smaller and benign lesion. Oncological outcomes are still difficult to compare between the different techniques due to lack of significant data (R0/R1 resections and number of lymph nodes harvested) and the high variability in the proportion of malignant cases in different series. However, literature reports a negative margin rate of $95.7 \%-100 \%$ for $\mathrm{RDP}^{16,30-35}$ ( similar to ODP on comparison ${ }^{30,33-35}$ ). Number of lymph nodes harvested seems to be adequate according to the criteria adopted for good oncological practice. ${ }^{16,30-36}$ Long-term results favoring oncological adequacy of minimally invasive technique for malignancy are not still available.

RDP-related morbidity is usually high (12\%-70\%), even if lower than ODP $8,47,48$; even though most series do not report severity classification, average morbidity is of low-grade severity (eg, pleural effusion).

All RDP series report 0\% mortality. ${ }^{16,30-35}$

Only few articles analyze and compare costs, with incongruent conclusions. Waters et $\mathrm{al}^{30}$ report higher intraoperative costs for RDP compared to LDP and ODP, but it was compensated by a shorter hospital stay after RDP so that the total adjusted costs were more effective for RDP $(\$ 11,904$, $\$ 12,900$, and $\$ 15,521$ for RDP, LDP, and ODP, respectively). Kang et $\mathrm{al}^{31}$ report a total cost higher for RDP than LDP $(\$ 8,304$ vs $\$ 3,861)$. It is difficult to compare the costs of MIDP between different health systems, but, generally speaking, robotic procedure is usually considered more expensive than conventional open and laparoscopic approaches.

In summary, robot-assisted DP is indeed feasible and safe. Minimally invasive DP has become the operation of choice for distal pancreatic lesions, except for bulky, locally advanced and proximal tumors. Robotic approach seems to be superior in achieving splenic preservation, but, except for this indication, it is questionable whether RDP really provides additional advantage over laparoscopic approach.

\section{Robotic total pancreatectomy}

Major indications for total pancreatectomy (TP) are tumor involving most of or the entire gland (eg, intraductal papillary mucinous neoplasms), in case of positivity of the pancreatic resection margin during PD for ductal adenocarcinoma, multiple primitive (eg, neuroendocrine) or metastatic tumors (eg, from renal cancer), and chronic pancreatitis with refractory pain. In selected patients, laparoscopy with or without robotic assistance proved to be advantageous, although experience with MITP is still confined to small series or isolated reports. ${ }^{49-53}$ TP with auto-transplant of islet cells has been described in patients with chronic pancreatitis. ${ }^{53-55}$ Characteristics of TP are the absence of risk of pancreatic fistula by definition, delicate dissection of the uncinate/posterior margin as it is in $\mathrm{PD}$, and the difficult biliary anastomoses due to the presence of regular bile duct size in most patients.

In a series of ten robotic total pancreatectomies (RTPs) by Zureikat et al, ${ }^{53}$ the operative time was 560 minutes, conversion rate $10 \%$, complication rate (Clavien-Dindo grade III-IV) $20 \%$, and average length of hospital stay was 10 days. They reported one readmission and one reoperation. Mortality was none.

Advantages of RTP versus open total pancreatectomy have been described in a case-matched study by Boggi et al. ${ }^{56}$ Eleven patients underwent RTP for benign or malignant disease and were compared to eleven patients with similar indications but without the availability of the robotic system at the time of scheduled surgery. They reported a $0 \%$ conversion rate, two vascular resections in each group, a longer operative time, but reduced blood loss in the robotic series. The length of hospital stay was similar between the two groups, but all the parameters evaluating recovery were advantageous for RTP.

\section{Robotic enucleation}

Pancreatic enucleation is an "extreme" parenchyma-sparing procedure and it is indicated for benign pancreatic tumors (eg, insulinomas, small neuroendocrine tumors, or benign cystic lesions, not requiring lymph node sampling) or solitary metastases from renal cell carcinoma. Enucleation is characterized by the most accurate preservation of pancreatic parenchyma, lack of anastomosis, and although it is associated with a significantly lower blood loss, pancreatic fistula rate is significantly high. Preoperative imaging and intraoperative ultrasound assessment are crucial prior to planning enucleation, in order to achieve negative margins and leave the main pancreatic duct intact. ${ }^{45,57}$

Zureikat et $\mathrm{al}^{58}$ reported ten robotic enucleations, with no perioperative mortality and a $30 \%$ incidence of pancreatic fistula. Mean operative time was 206 minutes, length of stay 5 days, and readmission was $30 \%$.

\section{Middle pancreatectomy}

Middle pancreatectomy (MP) is a rare but interesting pancreas-sparing resection, indicated in cases of benign or 
low-grade malignant tumors located in the pancreatic neck or proximal body, where the surgical purpose is to achieve a radical resection with preservation of full exocrine and endocrine pancreatic functionality ${ }^{59}$ The minimally invasive approach has not been widely described in the literature, and there are only a few reports available on the use of robotic platform. Results of robotic MP compared to open MP were evaluated in a small series by Kang et al: ${ }^{60}$ no differences were observed in terms of overall complication rate, perioperative mortality, and length of stay; the robotic series had a lower blood loss, but a longer operative time compared to open. The approach described by Kang was hybrid for three patients out of five (laparoscopic resection and robotic reconstruction), with pancreaticogastrostomy preferred over pancreaticojejunostomy. Giulianotti et a ${ }^{61}$ described the first series of three totally robotic MPs. The mean operative time was 320 minutes and the mean length of hospital stay was 9 days for patients with no complications and 27 days for patients complicated by a grade B (according to the International Study Group on Pancreatic Fistula) pancreatic fistula. Conversion and mortality rate were nil. Zureikat et al, ${ }^{58}$ in their series of 13 robotic MPs, reported $92 \%$ incidence of pancreatic fistula and a mean operative time of 394 minutes; there were two cases of conversion to open surgery and one reoperation. Length of hospital stay was 8 days. All the series reported a $0 \%$ incidence of pancreatic or endocrine insufficiency during follow-up. ${ }^{39}$

\section{Robotic Beger's procedure}

Zhan et $\mathrm{l}^{62}$ reported four cases of robot-assisted duodenumpreserving pancreatic resections (robotic Beger's procedure). Two patients had a serous cystadenoma, one had an insulinoma, and one had chronic pancreatitis. Pancreatic fistula rate and average length of stay were not low (75\% and 35.8 days, respectively), although they reported a satisfactory mean operative time (298.8 minutes) and mean operative blood loss (425 mL).

\section{Discussion}

The pancreatic gland is a complex anatomical organ due to its deep location and tight connections with the surrounding vessels, making surgical procedures often complex and difficult. Furthermore, pancreatic cancer has increased local invasion and distant metastasis in its early stages, adding huge disadvantages for surgeons.

Minimally invasive approaches have radically changed the history of pancreatic surgery during the last 2 decades, wherein they have been extended to oncological surgery. The laparoscopic approach limited to distal pancreatectomies and enucleations gained wide diffusion; otherwise, laparoscopic resections of the head of the pancreas still represent a perquisite of few skilled minimally invasive surgeons who approached pancreatic surgery.

Introduction of the robotic platform in the last decade has overcome the high level of technical skills required to approach the pancreas; besides, robotic device has some added advantages compared to even laparoscopy. Robot-assisted surgery has many advantages such as smaller incisions, faster recovery, restoration of eye-hand coordination, enhanced $3 \mathrm{D}$ vision, improved movement precision, and ergonomics due to Endowrist technology with seven degrees of freedom. Last but not the least, robotic platform requires a faster learning curve, considering several endpoints such as operating time, blood loss, complications rate, and readmission rate.

Today there have been many controversies on the role of minimally invasive surgery for pancreatic malignancies, including the effectiveness of radical resection in terms of extended local resection of the infiltrated pancreatic capsule, extension of lymphadenectomy, and major vessels' dissection and/or resection. Further debate focuses on the questionable real benefits for patients. However, considering the increased operating time of robotic procedures compared to standard open surgery, robotic-assisted pancreatic resections have shown to be equally feasible in terms of oncological outcomes and postoperative complications. Its remarkable benefits due to being less invasive and causing decreased blood loss, less surgical trauma, and faster recovery confer an important role to the robotic platform representing the fundamental basis for further researches.

In general, robotic surgery is often criticized for the high costs involved. Robotic prostatectomy is the first, and actually the only one, robotic procedure widely accepted as the gold standard. At the dawn of this era, several groups have shown how this procedure is not cost-effective despite reduced morbidity and length of stay. ${ }^{63,64}$ Only little data are available on robotic pancreatic surgery costs. Two groups have reported that the higher robotic costs were offset by a reduction in length of stay ${ }^{65,66}$ Future competition in the development of robotic technology should potentially lead to further cost reduction.

The current level of evidence is based on comparative studies compromised by strong bias in patient selection and data analysis. Randomized controlled trials (RCTs) are mandatory, but still literature is lacunar. Unfortunately, RCTs, even multicenter ones, are difficult to conduct because of limited availability of the robotic platform, consent issues, 
and often inadequate statistical power of the experimental case series.

In conclusion, experienced pancreatic surgeons in high-volume centers should continue to perform robotic pancreatic surgery and collect prospective data (eventually on a multi-institutional basis). Oncological outcome and more accurate long-term data will be necessary to definitively assess a proper role of this technology in pancreatic surgery field. Evidences encourage the use of robotic technology, but proper RCTs and survival analyses are still lacking.

\section{Disclosure}

The authors report no conflicts of interest in this work.

\section{References}

1. Gagner M, Pomp A, Herrera MF. Early experience with laparoscopic resections of islet cell tumors. Surgery. 1996;120(6):1051-1054.

2. Cuschieri A, Jakimowicz JJ, van Spreeuwel J. Laparoscopic distal 70\% pancreatectomy and splenectomy for chronic pancreatitis. Ann Surg. 1996;223(3):280-285.

3. Teh SH, Tseng D, Sheppard BC. Laparoscopic and open distal pancreatic resection for benign pancreatic disease. J Gastrointest Surg. 2007;11(9):1120-1125.

4. Goh BK, Tan YM, Chung YF, et al. Critical appraisal of 232 consecutive distal pancreatectomies with emphasis on risk factors, outcome, and management of the postoperative pancreatic fistula: a 21-year experience at a single institution. Arch Surg. 2008;143(10):956-965.

5. Luo Y, Liu R, Hu MG, Mu YM, An LC, Huang ZQ. Laparoscopic surgery for pancreatic insulinomas: a single-institution experience of 29 cases. J Gastrointest Surg. 2009;13(5):945-950.

6. Vezakis A, Davides D, Larvin M, McMahon MJ. Laparoscopic surgery combined with preservation of the spleen for distal pancreatic tumors. Surg Endosc. 1999;13(1):26-29.

7. Green PS, Hill JW, Jensen JF, Shah A. Telepresence surgery. IEEE Engineering in Medicine and Biology Magazine. 1995;14(3): 324-329.

8. Giulianotti PC, Coratti A, Angelini M, et al. Robotics in general surgery: personal experience in a large community hospital. Arch Surg. 2003;138(7):777-784.

9. Melvin WS, Needleman BJ, Krause KR, Ellison EC. Robotic resection of pancreatic neuroendocrine tumor. J Laparoendosc Adv Surg Tech A 2003;13(1):33-36.

10. Boone BA, Zenati M, Hogg ME, et al. Assessment of quality outcomes for robotic pancreaticoduodenectomy: identification of the learning curve. JAMA Surg. 2015;150(5):416-422.

11. Joyce D, Morris-Stiff G, Falk GA, El-Hayek K, Chalikonda S, Walsh RM. Robotic surgery of the pancreas. World J Gastroenterol. 2014;20(40):14726-14732.

12. Kendrick ML. Laparoscopic and robotic resection for pancreatic cancer. Cancer J. 2012;18(6):571-576.

13. Gagner M, Pomp A. Laparoscopic pancreatic resection: is it worthwhile? J Gastrointest Surg. 1997;1(1):20-25.

14. Narula VK, Mikami DJ, Melvin WS. Robotic and laparoscopic pancreaticoduodenectomy: a hybrid approach. Pancreas. 2010;39(2): $160-164$.

15. Fernandes E, Giulianotti PC. Robotic-assisted pancreatic surgery J Hepatobiliary Pancreat Sci. 2013;20(6):583-589.

16. Giulianotti PC, Sbrana F, Bianco FM, et al. Robot-assisted laparoscopic pancreatic surgery: single-surgeon experience. Surg Endosc. 2010;24(7):1646-1657.
17. Chen S, Zhan Q, Chen JZ, et al. Robotic approach improves spleenpreserving rate and shortens postoperative hospital stay of laparoscopic distal pancreatectomy: a matched cohort study. Surg Endosc. Epub 2015 Mar 20.

18. Buchs NC, Addeo P, Bianco FM, Ayloo S, Benedetti E, Giulianotti PC. Robotic versus open pancreaticoduodenectomy: a comparative study at a single institution. World J Surg. 2011;35(12):2739-2746.

19. Chalikonda S, Aguilar-Saavedra JR, Walsh RM. Laparoscopic roboticassisted pancreaticoduodenectomy: a case-matched comparison with open resection. Surg Endosc. 2012;26(9):2397-2402.

20. Lai EC, Yang GP, Tang CN. Robot-assisted laparoscopic pancreaticoduodenectomy versus open pancreaticoduodenectomy: a comparative study. Int J Surg. 2012;10(9):475-479.

21. Zhou NX, Chen JZ, Liu Q, et al. Outcomes of pancreatoduodenectomy with robotic surgery versus open surgery. Int J Med Robot 2011;7(2):131-137.

22. Zhang J, Wu WM, You L, Zhao YP. Robotic versus open pancreatectomy: a systematic review and meta-analysis. Ann Surg Oncol. 2013;20(6):1774-1780.

23. Cirocchi R, Partelli S, Trastulli S, Coratti A, Parisi A, Falconi M. A systematic review on robotic pancreaticoduodenectomy. Surg Oncol. 2013;22(4):238-246.

24. Nigri G, Petrucciani N, La Torre M, et al. Duodenopancreatectomy: Open or minimally invasive approach? Surgeon. 2014;12(4):227-234.

25. Chen Y, Yan J, Yuan Z, Yu S, Wang Z, Zheng Q. A meta-analysis of robotic-assisted pancreatectomy versus laparoscopic and open pancreatectomy. Saudi Med J. 2013;34(12):1229-1236.

26. Boggi U, Signori S, De Lio N, et al. Feasibility of robotic pancreaticoduodenectomy. Br J Surg. 2013;100(7):917-925.

27. Fisher SB, Kooby DA. Laparoscopic pancreatectomy for malignancy. J Surg Oncol. 2013;107(1):39-50.

28. Adam MA, Choudhury K, Goffredo P, et al. Minimally Invasive Distal Pancreatectomy for Cancer: Short-Term Oncologic Outcomes in 1,733 Patients. World J Surg. 2015;39(10):2564-2572.

29. Rosales-Velderrain A, Bowers SP, Goldberg RF, et al. National trends in resection of the distal pancreas. World $J$ Gastroenterol. 2012;18(32):4342-4349.

30. Waters JA, Canal DF, Wiebke EA, et al. Robotic distal pancreatectomy: cost effective? Surgery. 2010;148(4):814-823.

31. Kang CM, Kim DH, Lee WJ, Chi HS. Conventional laparoscopic and robot-assisted spleen-preserving pancreatectomy: does da Vinci have clinical advantages? Surg Endosc. 2011;25(6):2004-2009.

32. Lai ECH, Tang CN. Robotic distal pancreatectomy versus conventional laparoscopic distal pancreatectomy: a comparative study for short-term outcomes. Front Med. 2015;9(3):356-360.

33. Lee SY, Allen PJ, Sadot E, et al. Distal pancreatectomy: A single institution's experience in open, laparoscopic, and robotic approaches. $J \mathrm{Am}$ Coll Surg. 2015;220(1):18-27.

34. Butturini G, Damoli I, Crepaz L, et al. A prospective non-randomised single-center study comparing laparoscopic and robotic distal pancreatectomy. Surg Endosc. Epub 2015 Jan 1.

35. Shakir M, Boone BA, Polanco PM, et al. The learning curve for robotic distal pancreatectomy: an analysis of outcomes of the first 100 consecutive cases at a high-volume pancreatic centre. $H P B$. 2015;17(7):580-586.

36. Dalla Bona E, Beltrame V, Liessi F, Sperti C. Fatal pneumococcal sepsis eleven years after distal pancreatectomy with splenectomy for pancreatic cancer. JOP. 2012;13(6):693-695.

37. Warshaw AL. Conservation of the spleen with distal pancreatectomy. Arch Surg. 1988;123(5):550-553.

38. Kimura W, Yano M, Sugawara S, et al. Spleen-preserving distal pancreatectomy with conservation of the splenic artery and vein: techniques and its significance. J Hepatobiliary Pancreat Sci. 2010;17(6): 813-823.

39. Milone L, Daskalaki D, Wang X, Giulianotti PC. State of the art of robotic pancreatic surgery. World J Surg. 2013;37(12): 2761-2770. 
40. Stafford AT, Walsh RM. Robotic surgery of the pancreas: the current state of the art. J Surg Oncol. 2015;112(3):289-294.

41. Daouadi M, Zureikat AH, Zenati MS, et al. Robot-assisted minimally invasive distal pancreatectomy is superior to the laparoscopic technique. Ann Surg. 2013;257(1):128-132.

42. Winer J, Can MF, Bartlett DL, Zeh HJ, Zureikat AH. The current state of robotic-assisted pancreatic surgery. Nat Rev Gastroenterol Hepatol. 2012;9(8):468-476.

43. Bassi C, Dervenis C, Butturini G, et al; International Study Group on Pancreatic Fistula Definition. Postoperative pancreatic fistula: an international study group (ISGPF) definition. Surgery. 2005;138(1):8-13.

44. Zhou W, Lv R, Wang X, Mou Y, Cai X, Herr I. Stapler vs suture closure of pancreatic remnant after distal pancreatectomy: a meta-analysis. $\mathrm{Am}$ J Surg. 2010;200(4):529-536.

45. Liang S, Hameed U, Jayaraman S. Laparoscopic pancreatectomy: indications and outcomes. World J Gastroenterol. 2014;20(39): 14246-14254.

46. Kooby DA, Hawkins WG, Schmidt CM, et al. A multicenter analysis of distal pancreatectomy for adenocarcinoma: is laparoscopic resection appropriate? J Am Coll Surg. 2010;210(5):779-787.

47. Jayaraman S, Gonen M, Brennan MF, et al. Laparoscopic distal pancreatectomy: evolution of a technique at a single institution. $\mathrm{J} \mathrm{Am} \mathrm{Coll}$ Surg. 2010;211(4):503-509.

48. DiNorcia J, Schrope BA, Lee MK, et al. Laparoscopic distal pancreatectomy offers shorter hospital stays with fewer complications. J Gastrointest Surg. 2010;14(11):1804-1812.

49. Giulianotti PC, Addeo P, Buchs NC, Bianco FM, Ayloo SM. Early experience with robotic total pancreatectomy. Pancreas. 2011;40(2):311-313.

50. Heidt DG, Burant C, Simeone DM. Total pancreatectomy: indications, operative technique, and postoperative sequelae. J Gastrointest Surg. 2007;11(2):209-216.

51. Dallemagne B, de Oliveira AT, Lacerda CF, D’Agostino J, Mercoli H, Marescaux J. Full laparoscopic total pancreatectomy with and without spleen and pylorus preservation: a feasibility report. $J$ Hepatobiliary Pancreat Sci. 2013;20(6):647-653.

52. Casadei R, Marchegiani G, Laterza M, et al. Total pancreatectomy: doing it with a mini-invasive approach. JOP. 2009;10(3):328-331.

53. Zureikat AH, Nguyen T, Boone BA, et al. Robotic total pancreatectomy with or without autologous islet cell transplantation: replication of an open technique through a minimal access approach. Surg Endosc. 2015;29(1):176-183.
54. Galvani CA, Rodriguez Rilo H, Samamé J, Porubsky M, Rana A, Gruessner RW. Fully robotic-assisted technique for total pancreatectomy with an autologous islet transplant in chronic pancreatitis patients: results of a first series. J Am Coll Surg. 2014;218(3):e73-78.

55. Bramis K, Gordon-Weeks AN, Friend PJ, et al. Systematic review of total pancreatectomy and islet autotransplantation for chronic pancreatitis. Br J Surg. 2012;99(6):761-766.

56. Boggi U, Palladino S, Massimetti G, et al. Laparoscopic robot-assisted versus open total pancreatectomy: a case-matched study. Surg Endosc. 2015;29(6):1425-1432.

57. Fernández-Cruz L, Molina V, Vallejos R, Jiménez Chavarria E, López-Boado MA, Ferrer J. Outcome after laparoscopic enucleation for non-functional neuroendocrine pancreatic tumours. HPB. 2012; 14(3):171-176.

58. Zureikat AH, Moser AJ, Boone BA, Bartlett DL, Zenati M, Zeh HJ 3rd. 250 robotic pancreatic resections: safety and feasibility. Ann Surg. 2013;258(4):554-562.

59. Crippa S, Bassi C, Warshaw AL. et al. Middle pancreatectomy: indications, short- and long-term operative outcomes. Annals of Surgery. 2007;246(1)69-76.

60. Kang CM, Kim DH, Lee WJ, Chi HS. Initial experiences using robot-assisted central pancreatectomy with pancreaticogastrostomy: a potential way to advanced laparoscopic pancreatectomy. Surg Endosc. 2011;25(4):1101-1106.

61. Giulianotti PC, Sbrana F, Bianco FM, Addeo P, Caravaglios G. Robotassisted laparoscopic middle pancreatectomy. J Laparoendosc Adv Surg Techn A. 2010;20(2):135-139.

62. Zhan Q, Deng XX, Han B, et al. Robotic-assisted pancreatic resection: a report of 47 cases. Int J Med Robot. 2013;9(1):44-51.

63. Yu HY, Hevelone ND, Lipsitz SR, Kowalczyk KJ, Hu JC. Use, costs and comparative effectiveness of robotic assisted, laparoscopic and open urological surgery. J Urol. 2012;187(4):1392-1398.

64. Hu JC, Gu X, Lipsitz SR, et al. Comparative effectiveness of minimally invasive vs open radical prostatectomy. JAMA. 2009; 302(14):1557-1564.

65. Jung MK, Buchs NC, Azagury DE, Hagen ME, Morel P. Robotic distal pancreatectomy: A valid option? Minerva Chir. 2013;68(5):489-497.

66. Wayne M, Steele J, Iskandar M, Cooperman A. Robotic pancreatic surgery is no substitute for experience and clinical judgment: An initial experience and literature review. World J Surg Oncol. 2013;11:160.
Robotic Surgery: Research and Reviews

\section{Publish your work in this journal}

Robotic Surgery: Research and Reviews is an international, peer reviewed, open access, online journal publishing original research, commentaries, reports, and reviews on the theory, use and application of robotics in surgical interventions. Articles on the use of supervisorycontrolled robotic systems, telesurgical devices, and shared-control

\section{Dovepress}

systems are invited. The manuscript management system is completely online and includes a very quick and fair peer review system, which is all easy to use. Visit http://www.dovepress.com/testimonials.php to read real quotes from published authors. 